\title{
Evaluation of richmond agitation sedation scale according to alveolar concentration of sevoflurane during a sedation with sevoflurane in ICU patients
}

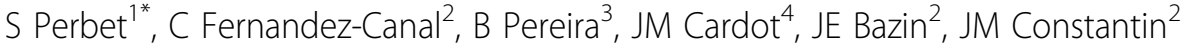 \\ From ESICM LIVES 2015 \\ Berlin, Germany. 3-7 October 2015
}

\section{Introduction}

In ICU sedation, use of inhalated gaz has interesting qualities, but remains limited due to lack of available and appropriate material. A new medical device (Mirus ${ }^{\text {TM }}$ (Pall)) allows feedback of the delivered flow rate from the targeted minimal alveolar concentration (MAC). Sedation is usually monitored by the RASS (Richmond Assessment Sedation Score).

\section{Objectives}

The objective of this study was to describe the values of RASS corresponding to different MAC or sevoflurane expired fraction (FeSevo) in sedated patients.

\section{Methods}

This prospective, interventional study was approved by the appropriate Institutional Review Board (Comité de Protection des Personnes Sud-Est VI, Clermont-Ferrand, France; NCT02202720) and conducted in a 16-bed ICU. For each patient, the sevoflurane MAC were increased to 0.1 MAC every 30 minutes from MAC 0 until MAC 0.8 then reduced with the same steps. Sevoflurane was administered with the Mirus ${ }^{\mathrm{TM}}$ system. RASS was evaluated after $15 \mathrm{~min}$ of stability after changing the MAC. Statistical analysis was performed using STATA, $\mathrm{p}<0.05$ was considered significant.

\section{Results}

Thirty patients were included: 11 women and 19 men, median age was 57 years; $63 \%$ of patients were postoperatively, median IGSII was 29.7 and SOFA 5.6. Compared to MAC 0, RASS decreased significantly from

${ }^{1} \mathrm{CHU}$ Clermont Ferrand, Réanimation Adultes, Pôle Médecine PériOpératoire, Clermont-Ferrand, France

Full list of author information is available at the end of the article
MAC $0.1(\mathrm{p}<0.001)$ then stabilized from MAC 0.6. From MAC 0.2, a significant correlation was noted between Bispectral index (BIS) and sevoflurane dose, and between the BIS and RASS. For a target of RASS -5 , effective concentrations (EC) of sevoflurane were MAC 0.6 for EC50 and MAC 0.8 for EC95.

\section{Conclusions}

This study found a correlation between the RASS and also the FeSevo or MAC of sevoflurane. The decrease in the RASS was well correlated with the increase in the concentration of sevoflurane and decreased BIS. Sedation with inhalated sevoflurane administered by the Mirus $^{\mathrm{TM}}$ system allows stable concentrations of sevoflurane and was well correlated to the targeted level of sedation. EC50 and EC95 can be expressed from RASS -1 until RASS -5 .

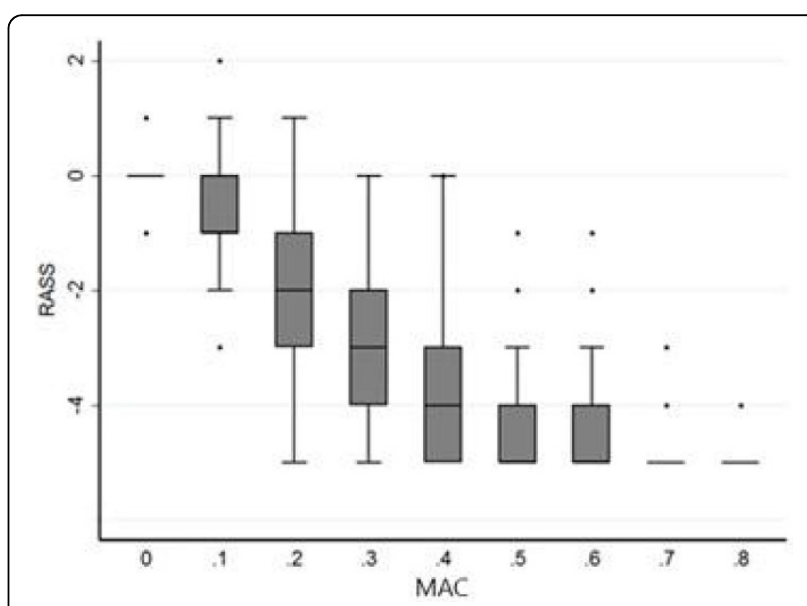

Figure 1 RASS \& sevoflurane MAC. 


\section{Authors' details}

${ }^{1} \mathrm{CHU}$ Clermont Ferrand, Réanimation Adultes, Pôle Médecine PériOpératoire, Clermont-Ferrand, France. ${ }^{2} \mathrm{CHU}$ Clermont Ferrand, Réanimation Adultes, Clermont-Ferrand, France. ${ }^{3} \mathrm{CHU}$ Clermont Ferrand, Biostatistics Unit, Clermont-Ferrand, France. ${ }^{4}$ Université d'Auvergne, Pharmacologie, ClermontFerrand, France.

Published: 1 October 2015

doi:10.1186/2197-425X-3-S1-A27

Cite this article as: Perbet et al:: Evaluation of richmond agitation

sedation scale according to alveolar concentration of sevoflurane during

a sedation with sevoflurane in ICU patients. Intensive Care Medicine

Experimental 2015 3(Suppl 1):A27.

\section{Submit your manuscript to a SpringerOpen ${ }^{\mathcal{O}}$ journal and benefit from:}

- Convenient online submission

- Rigorous peer review

- Immediate publication on acceptance

- Open access: articles freely available online

- High visibility within the field

- Retaining the copyright to your article

Submit your next manuscript at $\gg$ springeropen.com 